\title{
THE ELECTROCARDIOGRAM OF THE MOUNTAINEER AT HIGH ALTITUDE
}

BY

\author{
FREDERIC JACKSON* AND HYWEL DAVIES
}

From the General Hospital, Newcastle upon Tyne, and the National Heart Hospital, London

Received May 12, 1960

The British Sola Khumbu Expedition of 1959, led by Mr. J. H. Emlyn Jones, had as its objective the ascent of Ama'Dablam, an unclimbed Himalayan peak 22,400 ft. high, lying some ten miles south of Mount Everest. Secondary objectives of the expedition were to investigate the changes in the heart as shown by the electrocardiogram produced by climbing at high altitude, which is the subject of this paper, and an enquiry into the nature of the heart disease to be found among the little known Sherpa population who live at an elevation of about $12,000 \mathrm{ft}$.

Ama Dablam is a pinnacle of rock and ice of startling appearance (Fig. 2 and 4) which, to use Sir John Hunt's words, "appears utterly inaccessible, outrivalling the most sensational aspects of the Matterhorn" (Hunt, 1953). It lies in north-eastern Nepal, and is approached from Katmandu to within a few miles of its base by the route followed by post-war expeditions to Mount Everest (Fig. 1).

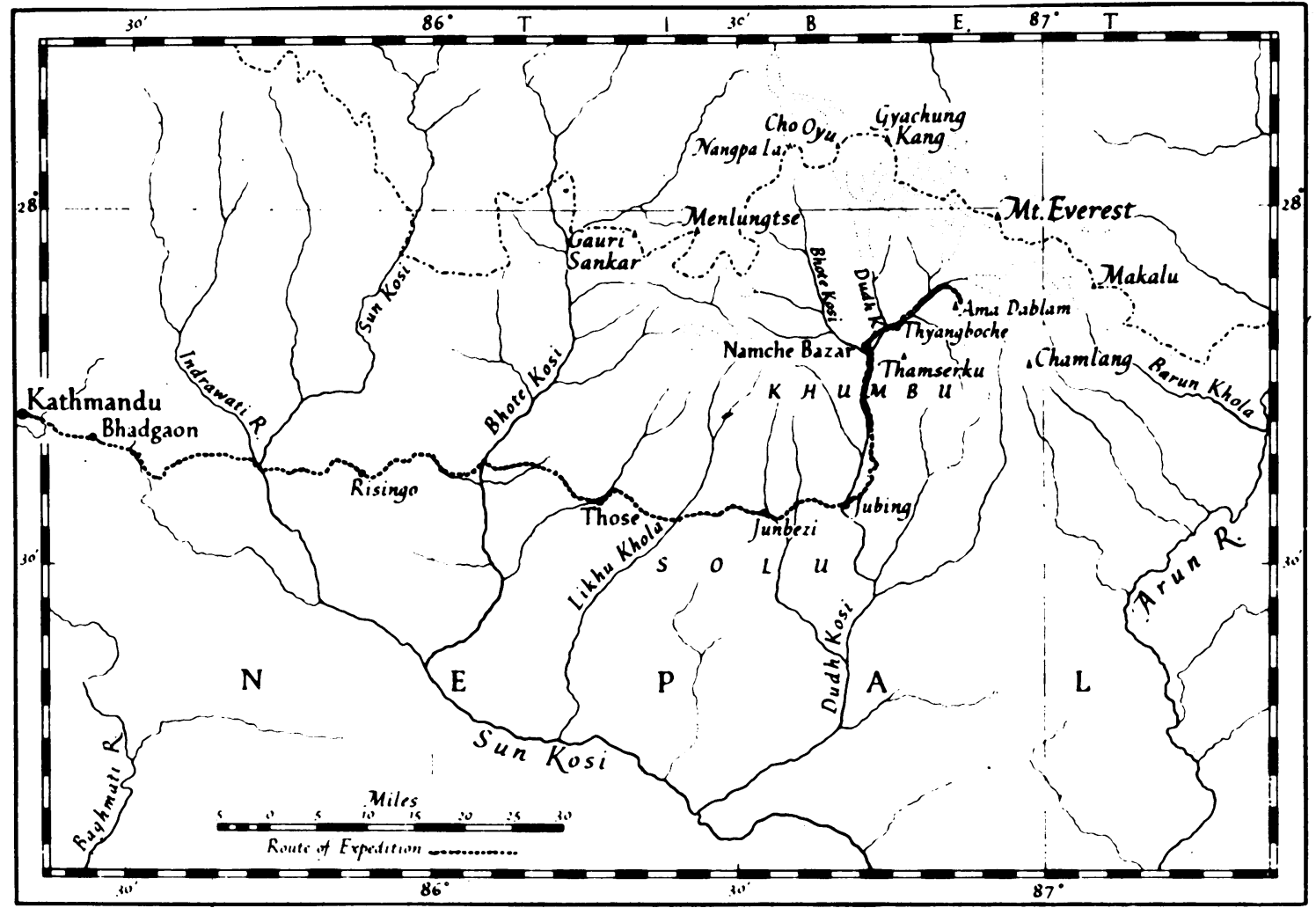

FIG. 1.-The route followed by the Expedition from Katmandu to the base of Ama Dablam. This map is published by permission of the Royal Geographical Society.

* Medical Officer to the Expedition 


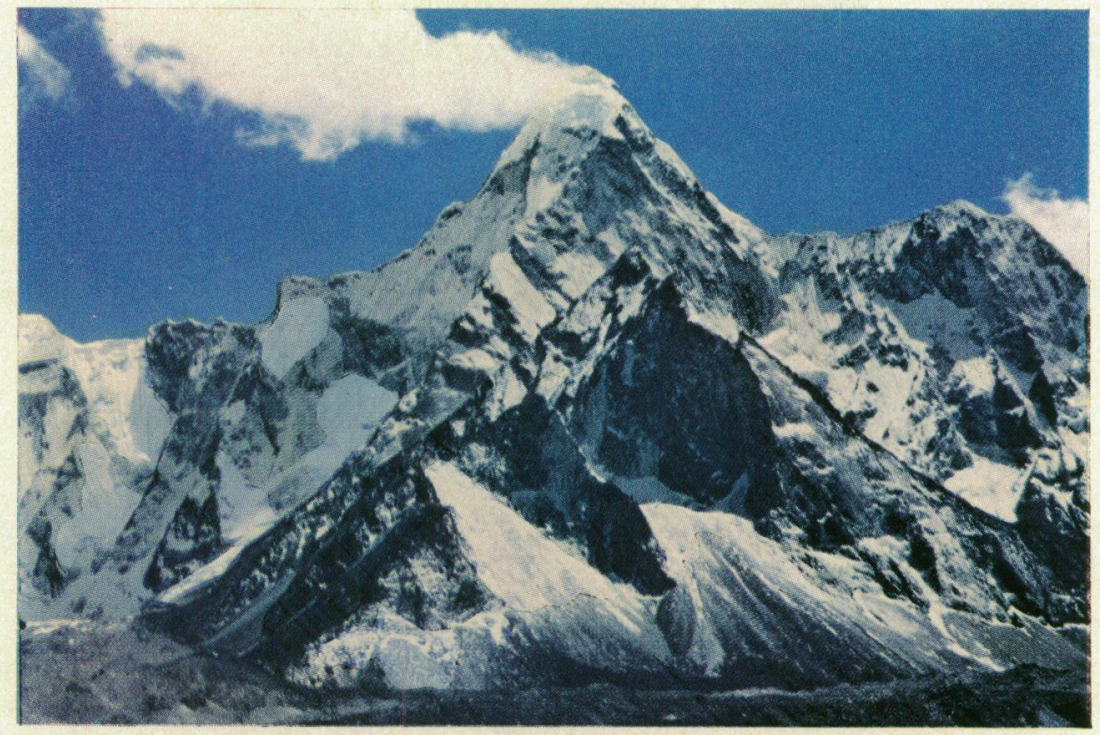

Fig. 2.-Ama Dablam, 22,400 feet, viewed from the north. The route lay along the sharp ridge, sloping upwards from the bottom left-hand corner towards the summit.

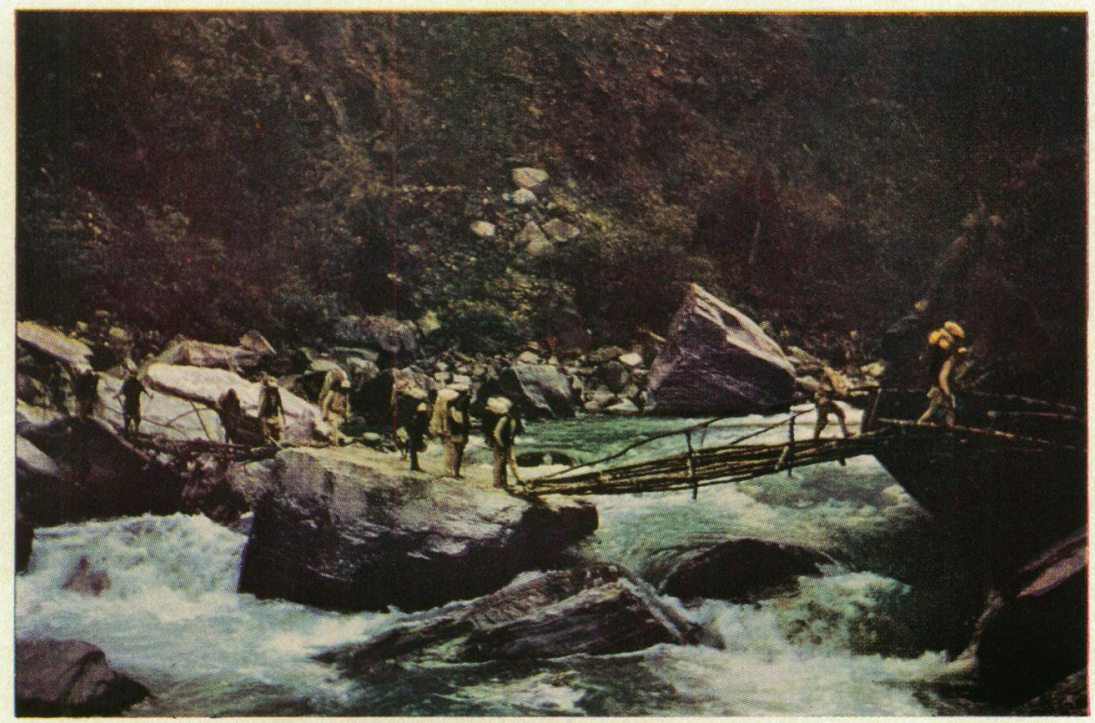

Fig. 3.-Tamang porters crossing the Dudh Kosi river. 
The party that assembled in Katmandu consisted of six Europeans, five men and one woman, a liaison officer nominated by the Nepalese Government, and seven Sherpas headed by the renowned Dawa Tensing of Kangchenjunga fame. Seventy-two Tamang porters were enrolled in Katmandu to carry the expedition's equipment which weighed about two tons, for there are no roads in Nepal beyond the outskirts of the capital. The journey from Katmandu to Namche Bazaar took sixteen days. The way lay eastwards across a succession of ridges, separated by deep valleys running north and south until the gorge of the Dudh Kosi river was reached. There the route turned due north into the heart of the Himalayas and to the home of the Sherpas. The track is accessible only on foot and there is neither wheeled nor animal transport except in the higher reaches where the yak is used as a beast of burden. Many of the bridges are temporary structures, liable to be washed away whenever there is a storm (Fig. 3).

On reaching Khumjung the largest of the Sherpa villages, situated at $12,000 \mathrm{ft}^{*}$ two hours beyond Namche Bazaar, the lowland porters were paid off and local Sherpas engaged for the carry to base-camp at the foot of the mountain three days further on. By the time the base-camp was reached at 16,400 $\mathrm{ft}$., the ups and downs of the way had entailed a total ascent of 48,000 $\mathrm{ft}$. and descent of $36,000 \mathrm{ft}$., which helped to make the party physically fit for the rigours to come. Many

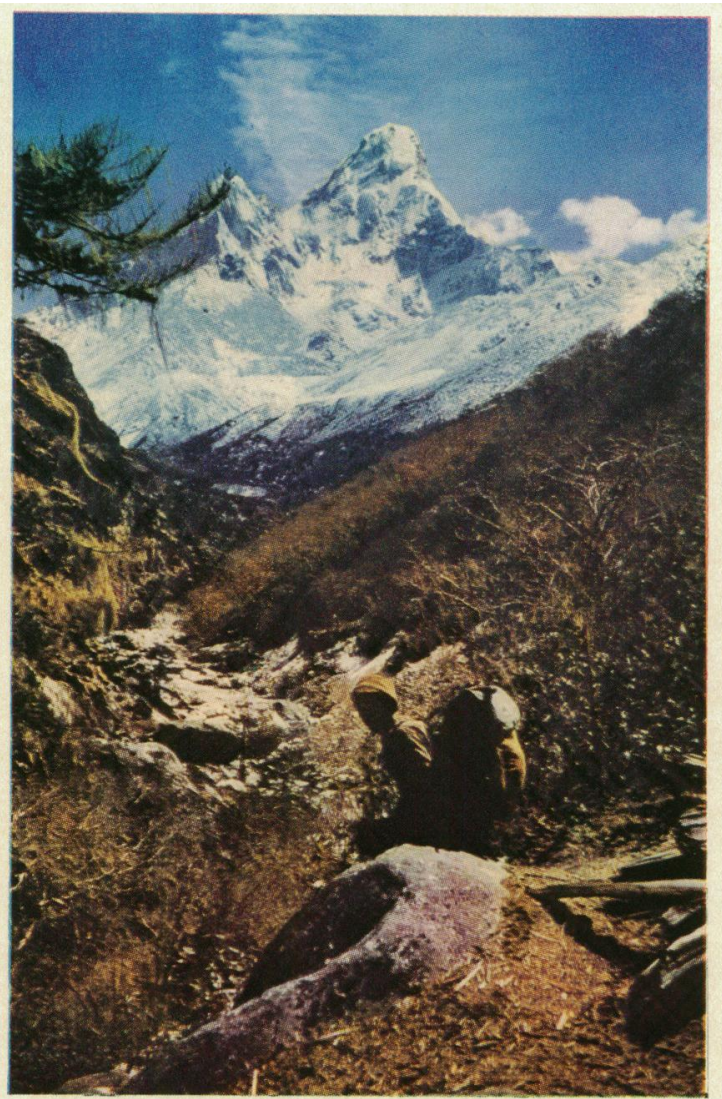

Fig. 4.-Ama Dablam. Looking up the Imja valley on the way to the Base Camp.

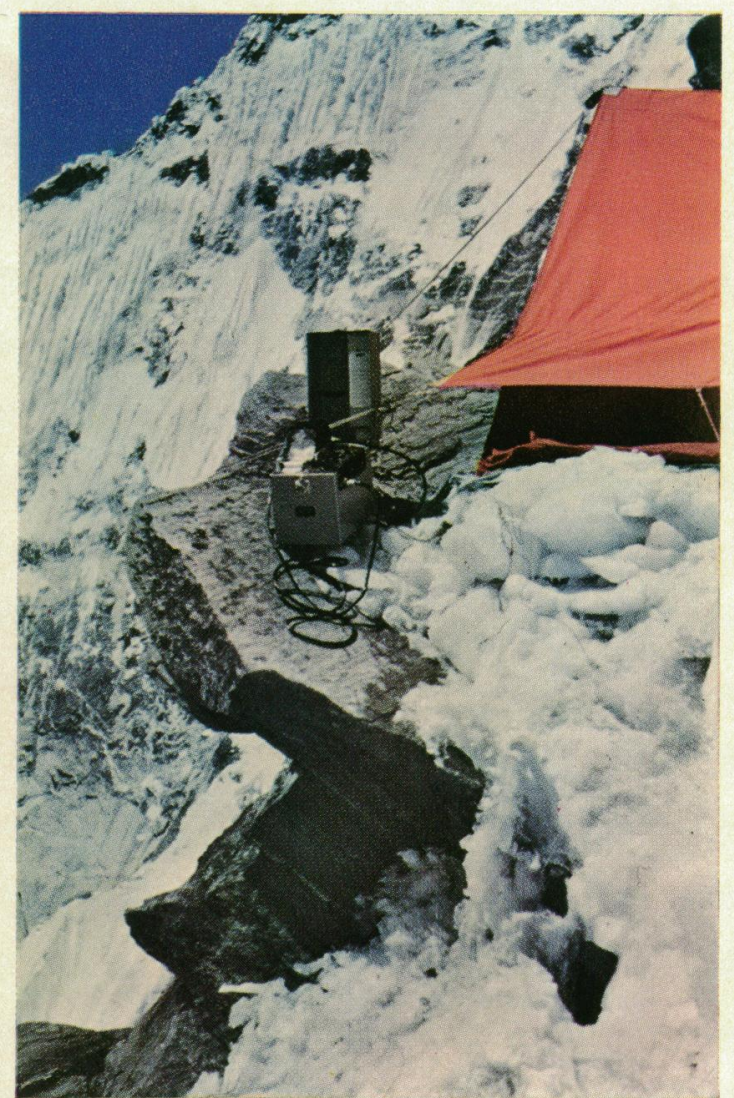

Fig. 5.-A rock ledge at over 19,000 feet where Camp II was perched, showing the Transrite electrocardiograph outside a tent.

* For the convenience of those who think in metres, each 1000 feet is nearly 305 metres, thus 12,000 feet is $3,658 \mathrm{~m}$., 17,650 feet is $5,380 \mathrm{~m}$., 19,150 feet is $5,838 \mathrm{~m}$., and 22,400 feet is $6,827 \mathrm{~m}$. 
inhabitants of Khumjung and the neighbouring villages were examined for the presence of heart disease, and blood samples were collected from about 130 people. At the Bhuddist monastery at nearby Thyangboche, the head lama and the head lama of the Rongbuk monastery in Tibet, who was staying there, were both examined and their cardiograms were recorded.

The attempt to climb Ama Dablam was made by way of its north ridge to which access was obtained by a subsidiary spur running north-east (Fig. 2); at the foot of this lay the base camp. The rock faces on either side of the ridge were too

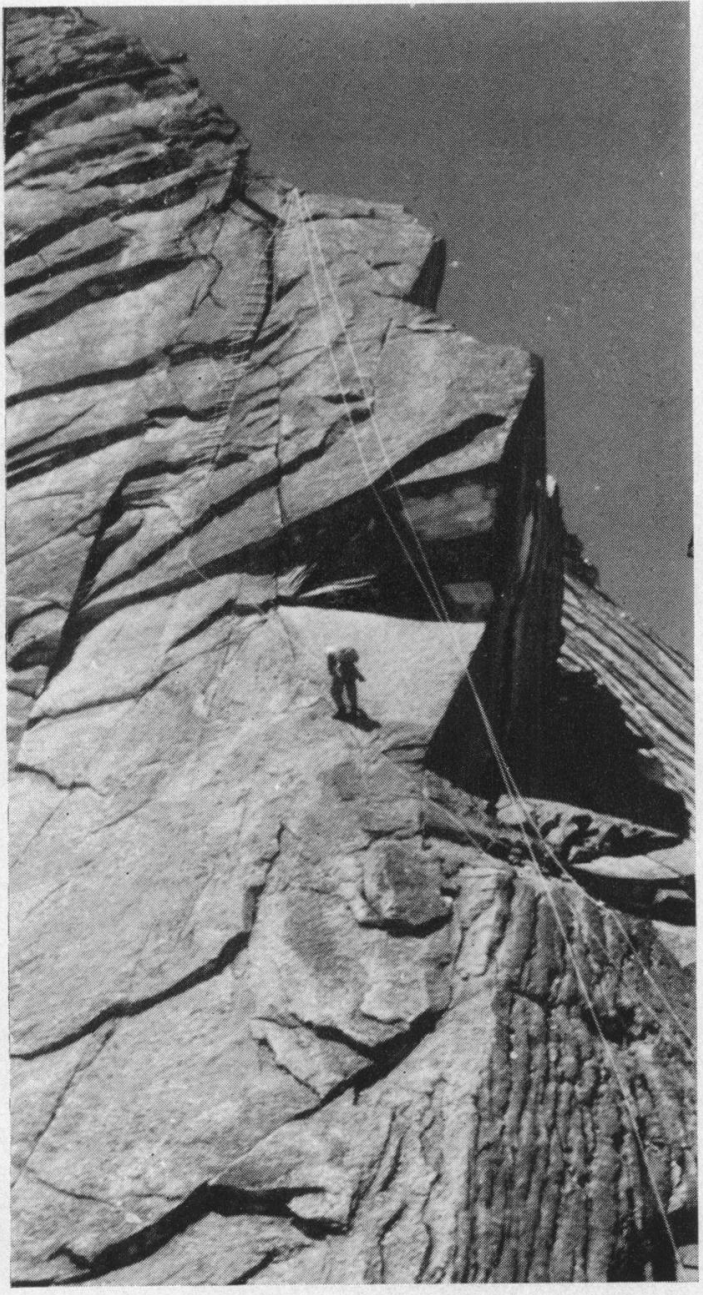

FIG. 6.-Steep slabs below Camp I up which the equipment, including the electrocardiograph, was hauled. An aerial ropeway was erected up the steeper section above the top of the rope ladder. precipitous to be climbed and were constantly swept by falls of rock and ice. Three main camps were established on the ridge at increasing heights, to which successive ascents were made carrying equipment and provisions in preparation for the attempt on the summit (Emlyn Jones, 1960). Unhappily the assault on the summit made by M. K. Harris and G. J. Fraser ended in a disaster in which they lost their lives. It is not known whether they reached the summit, which was clouded over, and were lost on the way down, or whether they fell before they reached the top: the early arrival of the monsoon, bringing heavy falls of snow, obliterated every trace.

The climbing in many places was technically both difficult and strenuous (Fig. 6). It was impossible to carry loads up the steeper sections and they had to be hauled up by ropes, and in one place, up an aerial ropeway. Throughout the length of the ridge, difficulty was experienced in finding level sites large enough to accommodate one or two tents. The first camp was established at 17,650 $\mathrm{ft}$., and the second camp, the highest point to which the electrocardiograph was taken, at 19,150 ft. (Fig. 5). From this camp we could see the summit of Mount Everest, behind the Lhotse-Nuptse ridge (Fig. 7 and 8). The bad weather that followed the accident forced a retreat from the ridge, and the electrocardiograph had to be abandoned in a tent at Camp II.

The machine was of the battery-operated transisterized type (Transrite) and was loaned by the Cambridge Instrument Company. It behaved faultlessly apart from a falling off in the amplification when the batteries became overcooled. Electrocardiograms were recorded of the European members of the party before leaving England, and again after their return three months later.

Tracings were made of the Nepalese liaison officer and of certain of the Sherpas before leaving Katmandu, which lies at an altitude of $4,350 \mathrm{ft}$. Thereafter, the tracings were repeated at increasing heights as the opportunity offered. Fifty tracings were obtained, including nine at $19,150 \mathrm{ft}$. They were recorded in the lying position, at least half an hour having elapsed since any strenuous exertion.

We have divided the climbers into two groups, which we have called for convenience the European group and the Sherpa group. The former consisted of six Europeans normally resident 


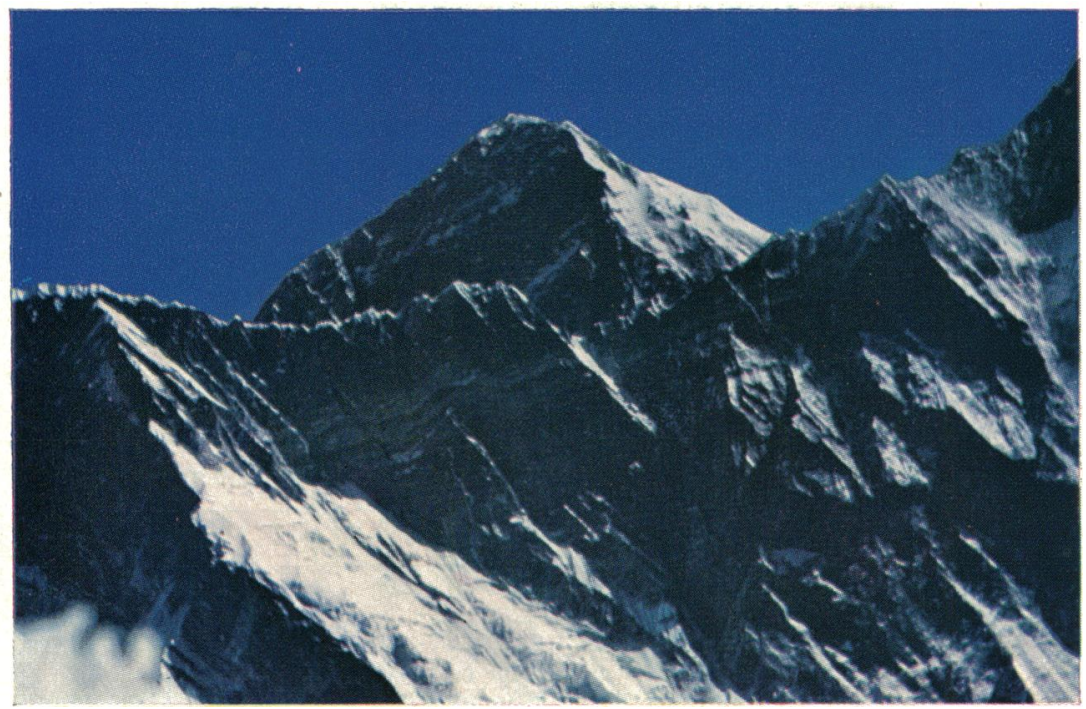

Fig. 7.-The summit of Everest behind the Lhotse-Nuptse ridge, taken from Camp II.

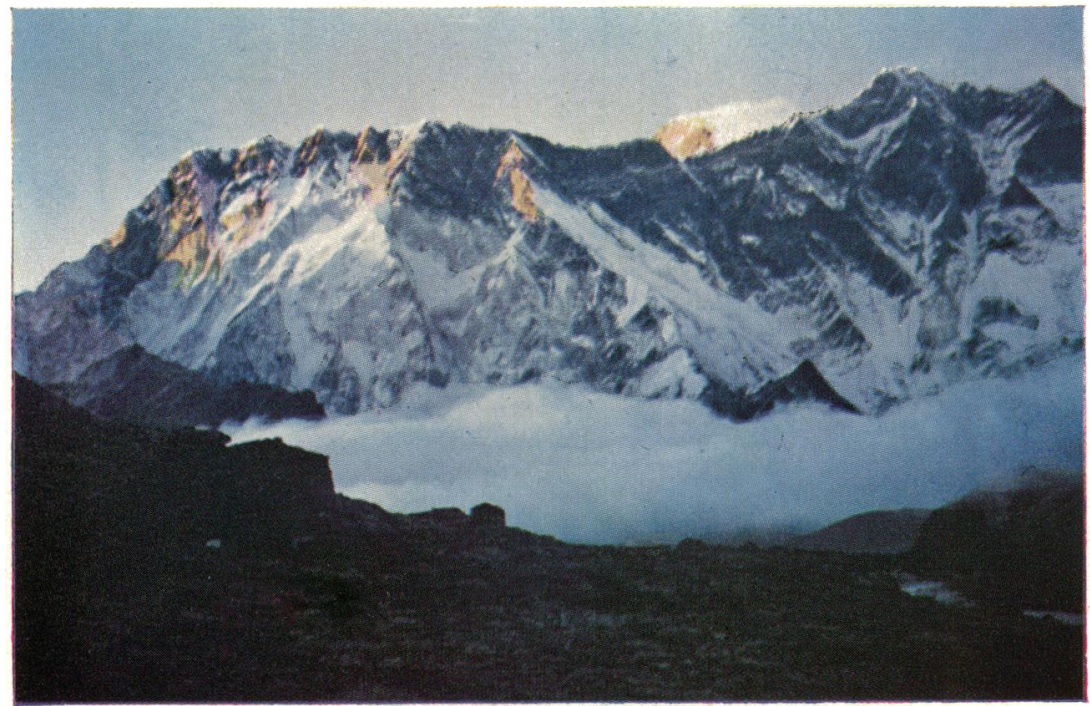

Fig. 8.-The light of the setting sun on Everest, with its plume, and on Nuptse to the left. 
at sea-level and one Nepalese of Indian descent living at 4,350 ft. The latter comprised the five Sherpas whose home was at $12,000 \mathrm{ft}$.

\section{RESULTS}

Resting Heart-Rate. Table I shows the resting heart rate at the various altitudes where tracings were recorded. The expected increase in rate with increasing altitude was usually present. There was little difference between the two groups in this respect, acclimatization of the Europeans being apparently adequate during the six weeks of climb.

TABLE I

The Resting Heart Rate at Increasing Altitudes

\begin{tabular}{|c|c|c|c|c|c|c|c|c|c|c|c|c|c|}
\hline \multirow{3}{*}{$\begin{array}{c}\text { Altitude } \\
\text { in } \\
\text { feet }\end{array}$} & \multirow{3}{*}{$\begin{array}{l}\text { Baro- } \\
\text { metric } \\
\text { pressure } \\
\mathrm{mm} . \mathrm{Hg}\end{array}$} & \multicolumn{12}{|c|}{ Pulse rate a minute } \\
\hline & & \multicolumn{7}{|c|}{ Europeans } & \multicolumn{5}{|c|}{ Sherpas } \\
\hline & & 1 & 2 & 3 & 4 & 5 & 6 & 7 & 1 & 2 & 3 & 4 & 5 \\
\hline Sea-level & 760 & 60 & 65 & 60 & 80 & 60 & - & - & - & - & - & - & - \\
\hline 4,000 & 655 & - & - & - & - & - & - & 55 & - & - & 65 & - & - \\
\hline 7,000 & 585 & - & - & - & - & - & $\overline{75}$ & - & $\overline{65}$ & $\overline{70}$ & - & $\overline{70}$ & - \\
\hline 11,700 & 488 & 75 & 70 & 75 & 70 & 60 & 70 & 50 & - & - & - & - & 65 \\
\hline 16,400 & 405 & 95 & 95 & 95 & 105 & - & 75 & 75 & 100 & 70 & 90 & 75 & 70 \\
\hline 17,900 & 380 & 75 & 100 & - & - & - & - & _ & 80 & 80 & - & - & - \\
\hline 19,150 & 367 & 105 & 100 & 105 & - & 85 & - & - & 100 & 80 & 100 & - & $\ldots$ \\
\hline Sea-level & 760 & 60 & 75 & - & 55 & 70 & - & - & - & - & - & - & 一 \\
\hline
\end{tabular}

The heart rate was taken from the electrocardiograms.

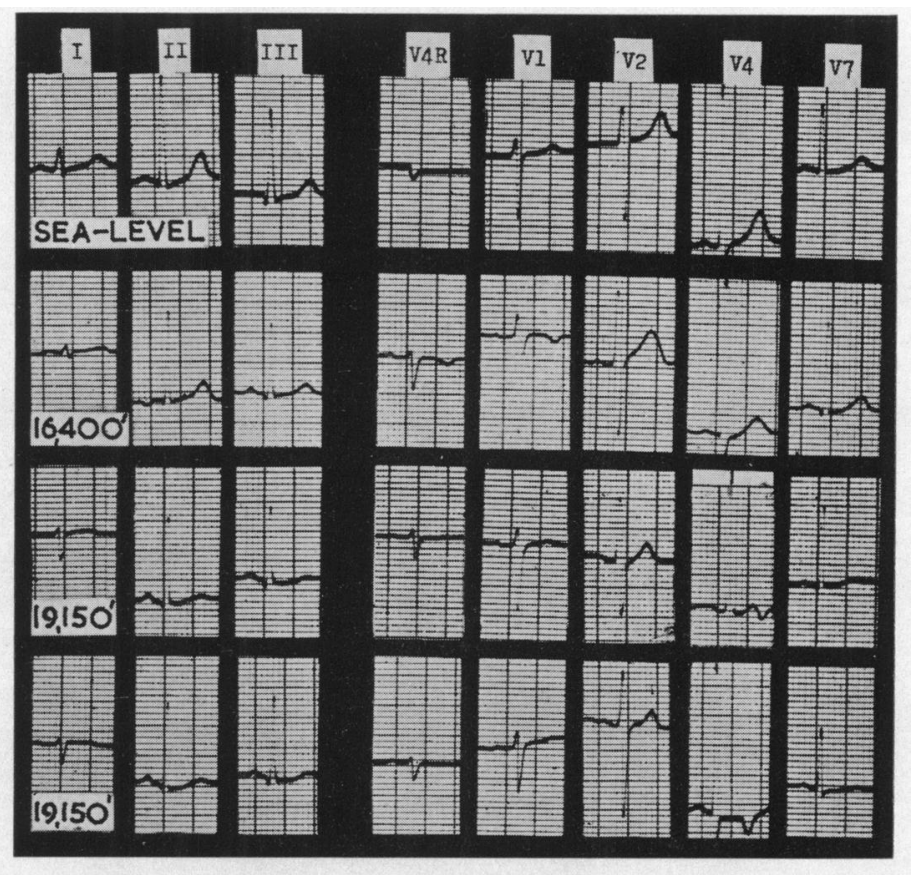

FIG. 9.-The electrocardiograms of Subject 1, European aged 44, showing right axis shift and inversion of $T$ in right chest leads and in V4 with increasing altitude. The third tracing was taken shortly after arrival at $19,150 \mathrm{ft}$. and the fourth a day later. The height in feet is marked on the left. 
$P$ Wave. No significant changes were seen in the amplitude of the $\mathrm{P}$ wave. In one of the European group and in one of the Sherpas there was some rightward shift of the ÂP vector, so that $\mathbf{P}$ became inverted in aVL. In one other case in the European group, this shift amounted to $35^{\circ}$, and $P$ became inverted in lead $\mathrm{I}$.

$P-R, Q R S$, and $Q-T$ Intervals. No noteworthy alterations occurred in these.

$Q R S$ Complex. It was here that the greatest changes were seen. When allowance is made for the lower amplification at high altitude (the standardization of the tracings taken at 19,150 $\mathrm{ft}$., was about two-thirds of normal) it becomes evident that the overall voltage of the QRS complex was greater than at sea-level, the increase being greater in the præcordial leads than in the limb leads.

More striking, however, was the appearance of right axis shift (Fig. 9-13). With increasing altitude $S$ in lead I became more prominent and sometimes even dominant (Fig. 16 and 17), the change occurring in both European and Sherpa groups. Tracings were obtained at 19,150 ft. in seven subjects, four Europeans and three Sherpas. Right axis deviation had developed in six of these, three in each group, all of whom had a relatively vertical axis initially. Table II expresses the values for

TABLE II

The Direction of the Mean QRS Vector at Various Altitudes

\begin{tabular}{|c|c|c|c|c|c|c|c|c|c|c|c|}
\hline \multirow{3}{*}{$\begin{array}{l}\text { Altitude } \\
\text { in feet }\end{array}$} & \multicolumn{11}{|c|}{$\begin{array}{l}\text { Direction of the mean QRS vector in the frontal plane, } \\
0^{\circ} \text { being horizontal and } 90^{\circ} \text { vertical }\end{array}$} \\
\hline & \multicolumn{7}{|c|}{ Europeans } & \multicolumn{4}{|c|}{ Sherpas } \\
\hline & 1 & 2 & 3 & 4 & 5 & 6 & 7 & 2 & 3 & 4 & 5 \\
\hline Sea-level & $75^{\circ}$ & $75^{\circ}$ & $70^{\circ}$ & $30^{\circ}$ & $20^{\circ}$ & - & - & - & - & - & 一 \\
\hline 4,000 & - & - & - & - & - & - & $90^{\circ}$ & $\overline{7}$ & $60^{\circ}$ & - & - \\
\hline $\begin{array}{r}7,000 \\
11700\end{array}$ & $\overline{80^{\circ}}$ & $\overline{80^{\circ}}$ & $\overline{90^{\circ}}$ & $\overline{30^{\circ}}$ & $\overline{30^{\circ}}$ & $\begin{array}{l}90^{\circ} \\
05^{\circ}\end{array}$ & $\overline{00^{\circ}}$ & $75^{\circ}$ & 二 & $65^{\circ}$ & $\overline{60^{\circ}}$ \\
\hline 16,400 & $80^{\circ}$ & $80^{\circ}$ & $105^{\circ}$ & $30^{\circ}$ & - & $\begin{array}{l}93 \circ \\
95^{\circ}\end{array}$ & $\begin{array}{l}90^{\circ} \\
90^{\circ}\end{array}$ & $\overline{80^{\circ}}$ & $\overline{75^{\circ}}$ & $\overline{65^{\circ}}$ & $85^{\circ}$ \\
\hline 17,900 & $85^{\circ}$ & $95^{\circ}$ & & & - & & & $95^{\circ}$ & & & \\
\hline 19,150 & $105^{\circ}$ & $105^{\circ}$ & $120^{\circ}$ & - & $40^{\circ}$ & - & - & $105^{\circ}$ & $90^{\circ}$ & - & - \\
\hline Sea-level & $75^{\circ}$ & $80^{\circ}$ & & $40^{\circ}$ & $30^{\circ}$ & - & - & & & - & - \\
\hline
\end{tabular}

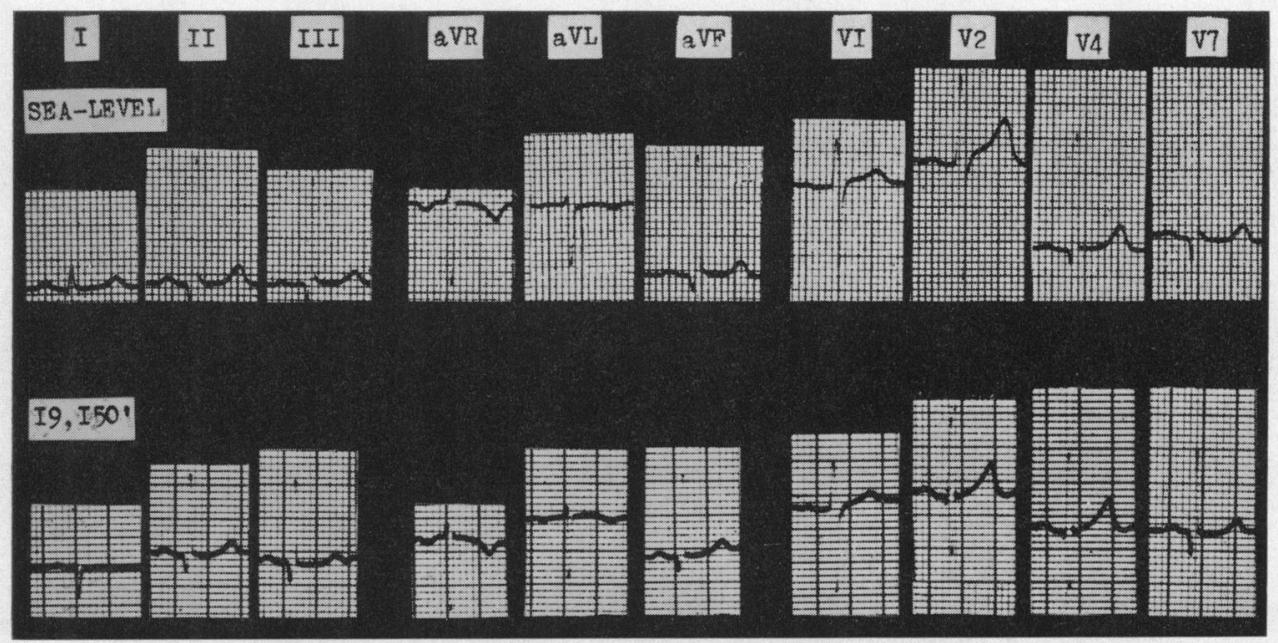

FIG. 10.-Subject 2, European aged 43, showing right axis shift. T normal in chest leads. One week earlier at $17,900 \mathrm{ft}$. T was inverted in V1 and blunted in V2 which, by mistake, is shown under V1, with a duplicate of V4 under V2. 
the direction of the mean QRS vector in the frontal plane at various altitudes. Directional changes in the horizontal and sagittal planes were small and inconsistent.

$S-T$ Segment. Depression of the S-T segment at high altitude was seen in two European subjects, these being in fact the oldest of the climbers, aged 44 and 53 years (Fig. 9 and 14). The changes were apparent in leads II, III, aVF, and the left præcordial leads. They were not seen in any of the Sherpas.

$T$ Wave. Changes in the $\mathrm{T}$ wave were of two kinds. First, inversion of $\mathrm{T}$ in the right chest leads

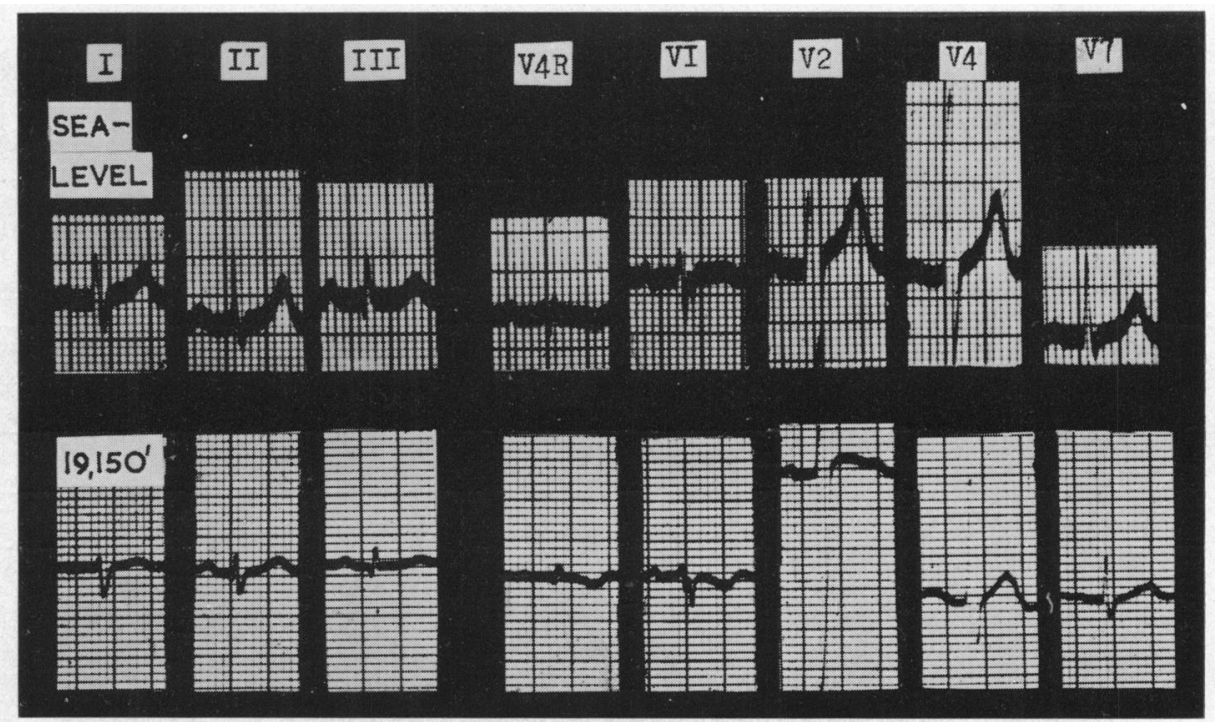

Fig. 11.-Subject 3, European aged 27, showing right axis shift, lowering of $T$ in V1, and blunting of $\mathrm{T}$ elsewhere.

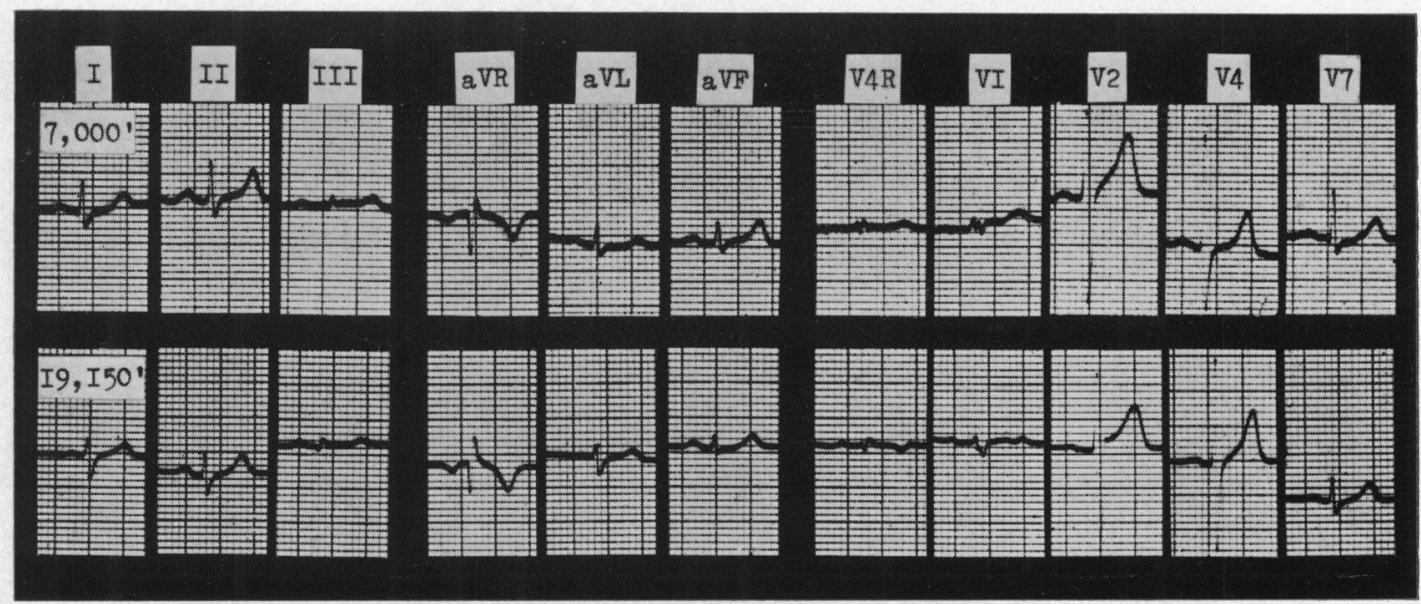

Fig. 12.-Subject 1, Sherpa aged 28 , normally resident at $12,000 \mathrm{ft}$., showing right axis shift and inversion of $\mathrm{T}$ in V4R at $19,150 \mathrm{ft}$. The height in feet is marked on the left. 


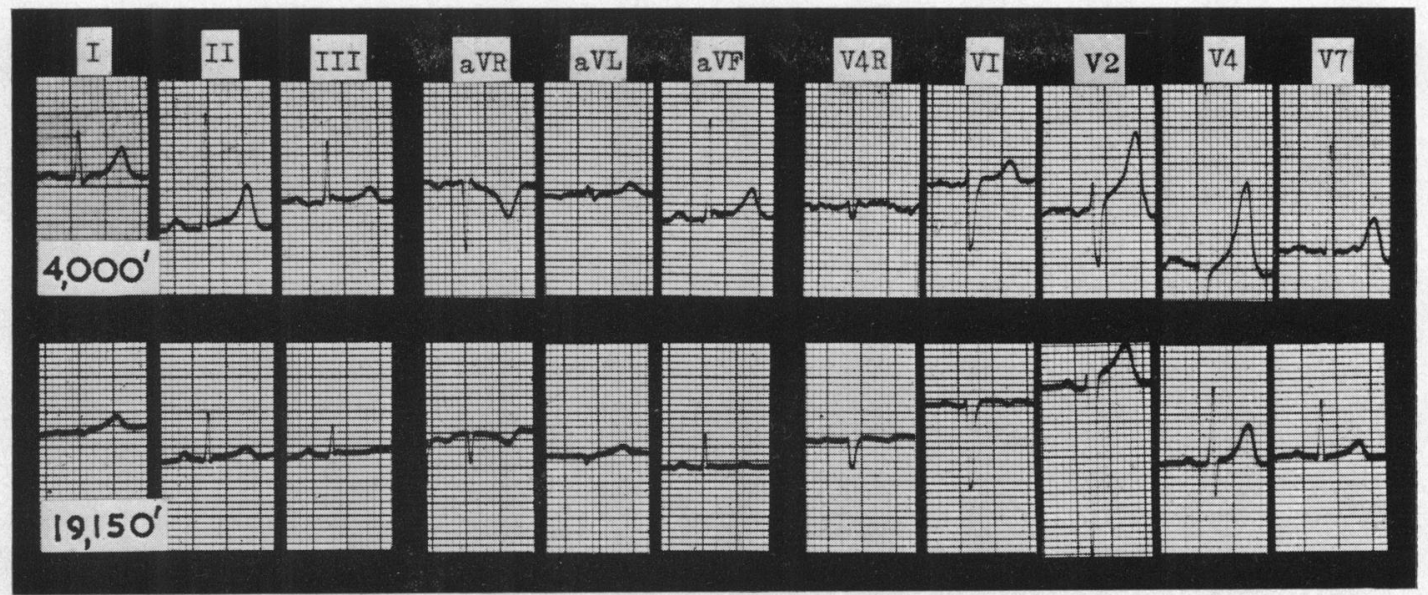

FIG. 13.-Subject 3, Sherpa aged 33, showing right axis shift and inversion of $T$ in V4R and flattening of $T$ in V1.

appeared or, if already present, deepened at high altitude in four of the seven members of the European group (Fig. 9, 11, and 16), and in four of the five Sherpas (Fig. 12, 13, and 17); in the remaining four subjects, none of whom were tested above $16,400 \mathrm{ft}$., the $\mathrm{T}$ wave did not alter significantly. Thus a lowering of the $\mathrm{T}$ wave in $\mathrm{V} 1$ was observed in all seven subjects whose cardiograms were recorded at $19,150 \mathrm{ft}$., and in one of the remaining five who were tested up to $16,400 \mathrm{ft}$. In three subjects, however, (two European and one Sherpa) the inversion of $T$ in the right chest leads was greater at $16,400 \mathrm{ft}$. in the early stages of acclimatization than it was later at 19,150 ft. (Fig. 9), and in Subject 2 (European group) $\mathrm{T}$ in V1 was upright shortly after arrival at $19,150 \mathrm{ft}$. (Fig. 10) but had become inverted next day after spending the night at that altitude (Fig. 16).

Secondly, lowering of the $T$ wave in left præcordial leads occurred at some period, though not consistently, in all seven members of the European group, but not to any significant degree in any of the Sherpas. In one subject $\mathrm{T}$ became frankly inverted in lead V4 and remained thus for at least 40 hours. It is not known how long this inversion per-

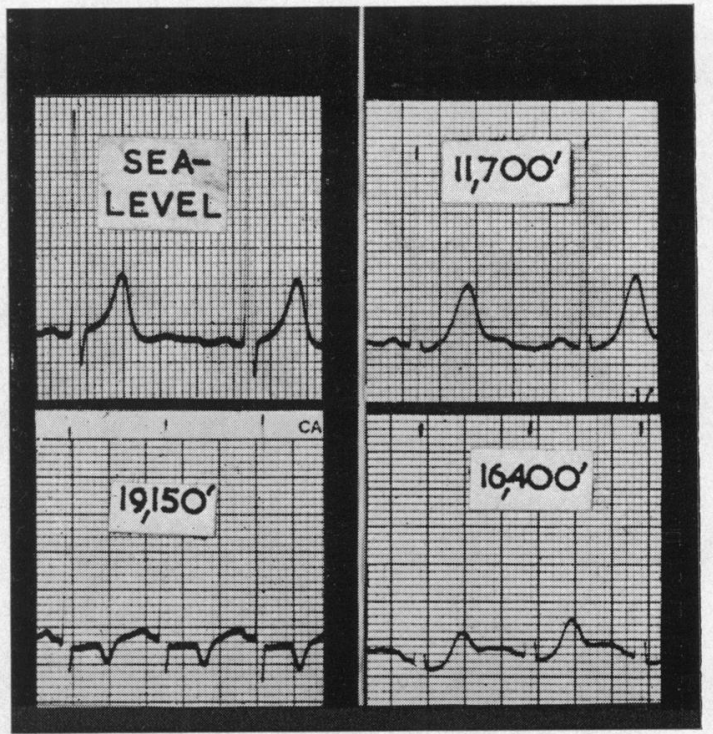

Fig. 14.-Lead V4 in Subject 1, aged 44, on the left, and Subject 4, aged 53, on the right, both European, showing $\mathbf{S}-\mathbf{T}$ and $\mathbf{T}$ changes at high altitude. The height in feet is marked on each record. sisted since the loss of the electrocardiograph prevented the recording of further tracings, but the $T$ wave was fully upright four weeks later after returning to sea-level. There was in this case coincident S-T depression (Fig. 9 and 14). At no time were there symptoms of cardiac ischæmia. In none of the four European subjects in whom a tracing was recorded after returning to sea-level, including Subject 1 whose tracing is reproduced in Fig. 9, were there any residual changes. 


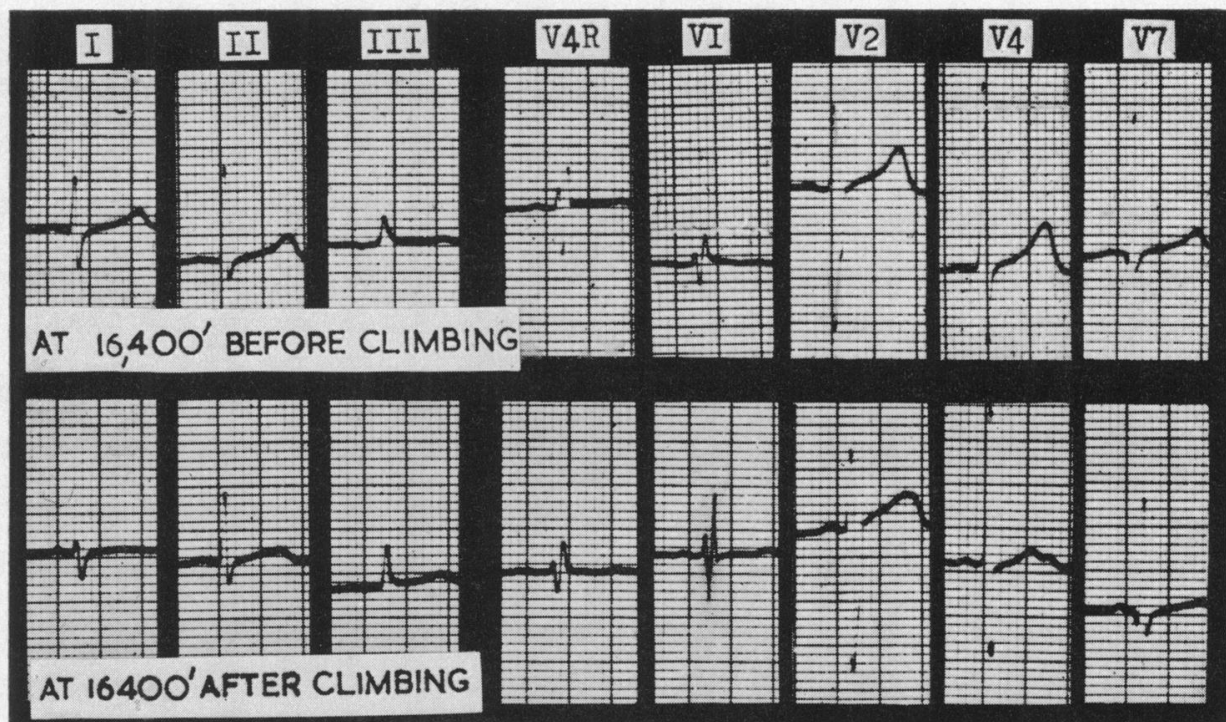

Fig. 15.-Subject 7, European group. Tracings taken at $16,400 \mathrm{ft}$. showing increased right axis deviation, taller $R^{\prime}$ in V1, and blunted T waves after a strenuous day's climbing to $18,500 \mathrm{ft}$.

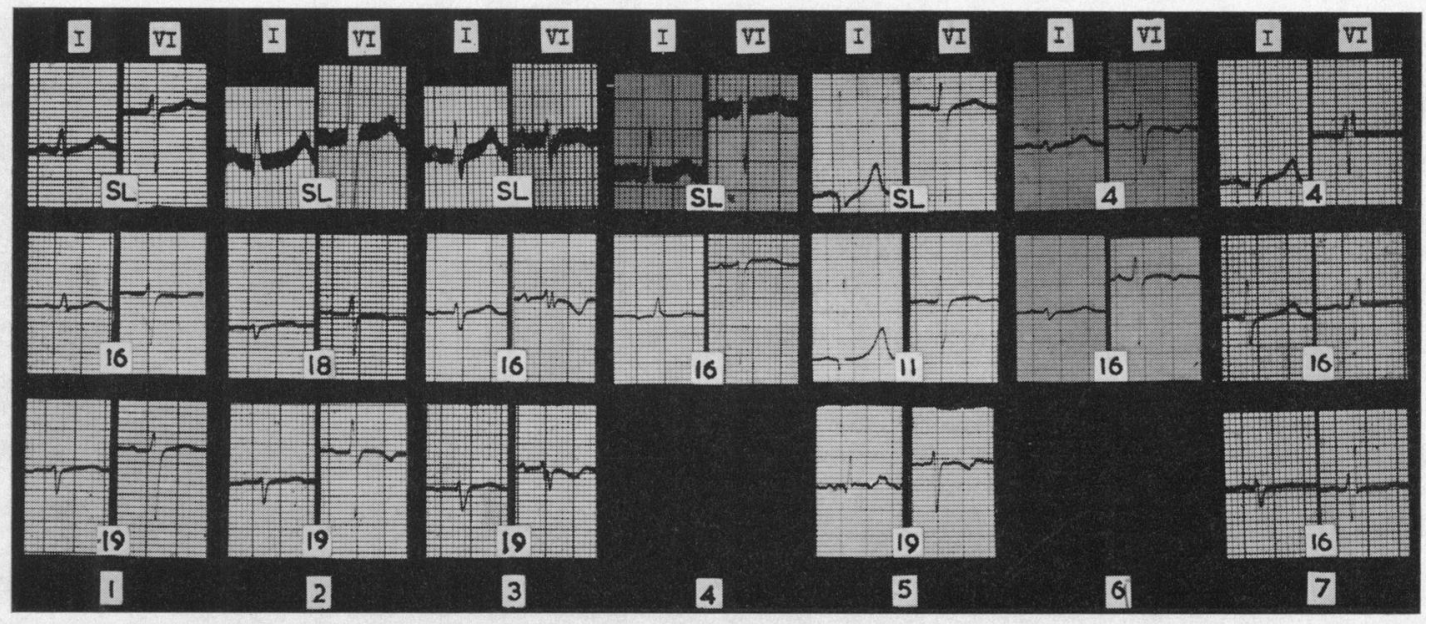

Fig. 16. - Composite picture of the seven members of the European group (1-7, below), showing leads I and V1 at different heights. The superimposed numbers represent the altitude in thousands of feet. SL, at sea-level. 


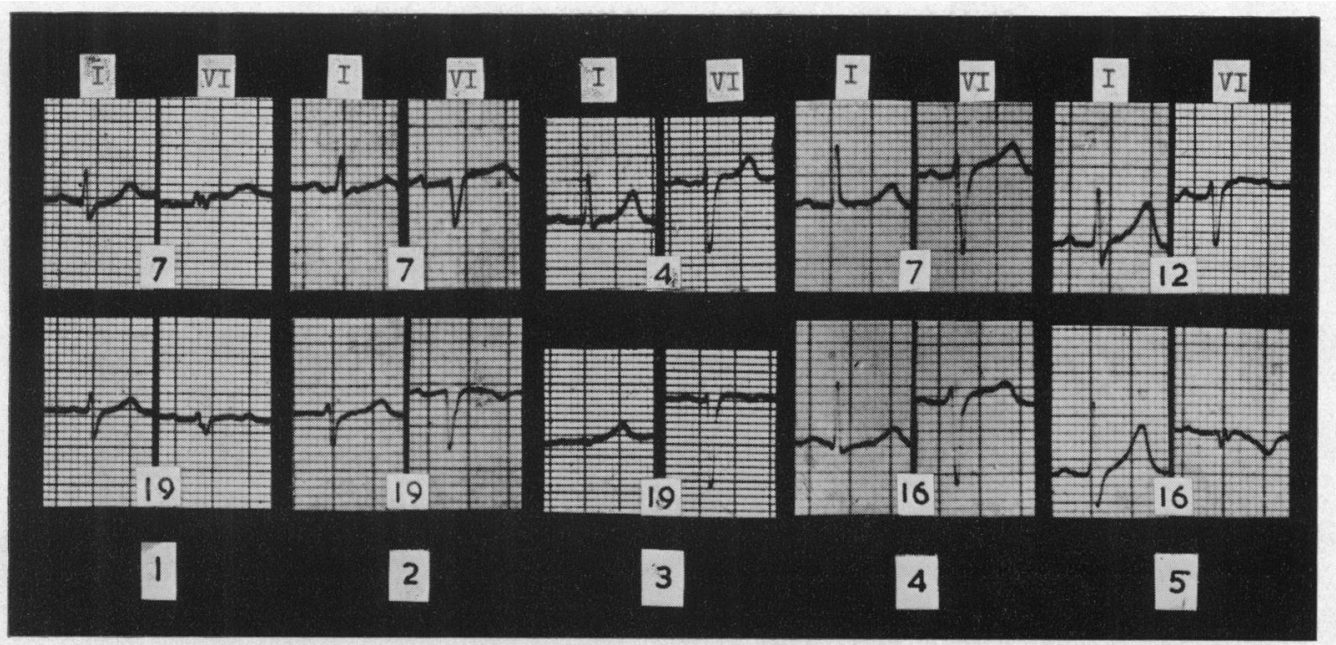

FIG. 17.-Composite picture of the five members of the Sherpa group (numbers 1-5, below), showing leads I and V1. Right axis deviation and inversion of T in V1 are seen in both European and Sherpa groups. The superimposed numbers $(4,7,12$, etc.) represent the altitude in thousands of feet.

\section{DISCUSSION}

The interpretation of these changes turns on two questions. The first is whether the right axis shift is the consequence solely of cardiac rotation or of increased right ventricular load. The second question is whether or not the T-wave changes over the left ventricle are the outcome of cardiac ischæmia.

QRS Changes. Ashman (1946) stated that when clockwise rotation of a vertical heart takes place about its longitudinal axis, such modifications of the QRS complex as we have described may occur. This leaves unanswered the question of why such a rotation should take place at high altitude, if in fact it does. Certainly hyperventilation is a feature of life under these conditions, the subject breathes more deeply, and the mean position of the diaphragm is probably lower than at sea-level. The normal lead III at high altitude resembled lead IIIR (lead III on full inspiration) at sea-level and the X-rays taken at the end of the expedition appear to show a lower diaphragm than at its beginning (Fig. 19). We doubt, however, if this is the whole explanation. The fullest possible inspiration at sea-level failed in Subject 1 to move the QRS axis rightwards far enough to produce right axis deviation (Fig. 18). In this context, Grant (1960) emphasises that when right axis deviation is the result of right ventricular hypertrophy in acquired emphysema, it is rarely of a degree greater than that seen here. Some of these changes resemble those that have been recorded in pulmonary embolism, pneumonia, and pneumothorax. In the latter situation the fact that right axis shift may occur whether the pneumothorax is on the right or the left side (Lepeschkin, 1951) makes it likely that it is a manifestation of right ventricular overload rather than of cardiac displacement.

$T$-wave Changes in Right Chest Leads. The T-wave changes seen in V1 are in keeping with the explanation that there is an increased load on the right side of the heart, and the frequency of the findings rules out variation in electrode placement as the cause. Furthermore, deep inspiration at sea-level in Subject 1 caused T in V1 to become more upright (Fig. 18) rather than the reverse, and therefore the lower position of the heart at high altitude was not responsible for the inversion. On the other hand the fact that the $T$ inversion was partially reversed later at the greatest altitude in three instances raises the question of whether humoral factors were also involved, and mention of these is made later on.

Thus, it seems likely that the right axis shift is due, in part at least, to the imposition of an $2 \mathrm{x}$ 


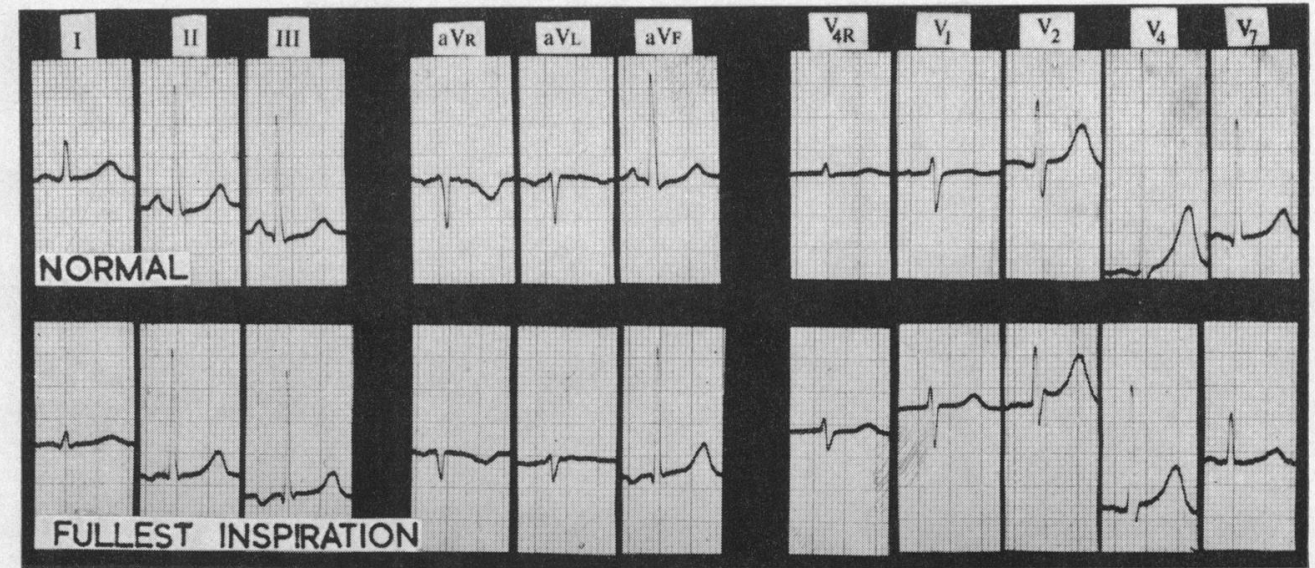

FIG. 18.-Subject 1, European, at sea level. Shows the effect of the deepest possible inspiration for comparison with the effect of high altitude (Fig. 9). Inspiration causes a much smaller movement of the mean QRS vector than that caused by ascent to high altitude (See text).

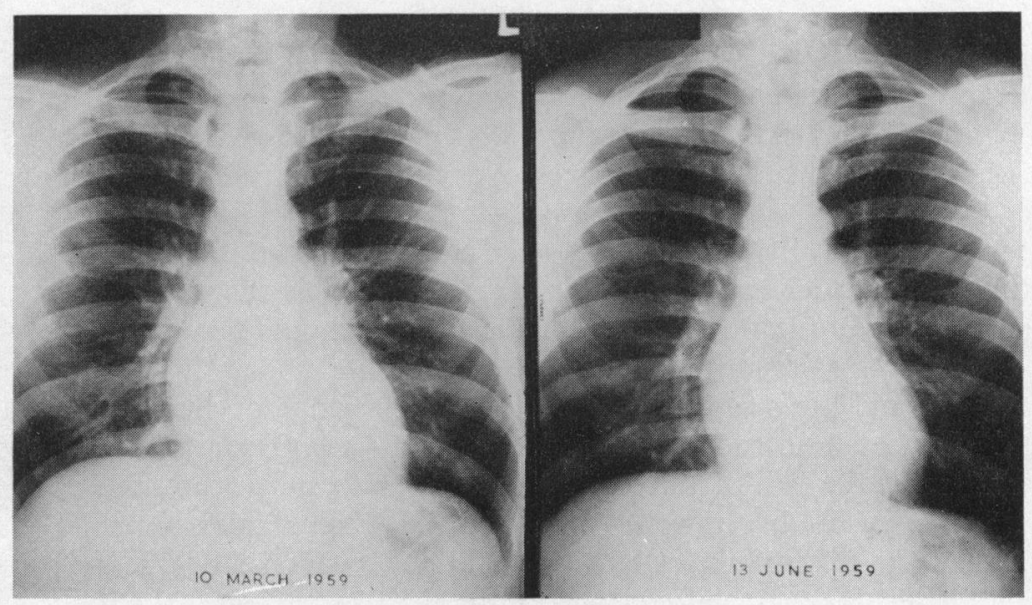

FIG. 19.-European, Subject 5. Six-foot teleradiograms on full inspiration at the beginning and end of the expedition, showing slight lowering of the diaphragm and slight reduction in the apparent size of the heart.

increased load on the right ventricle, and the factors that could contribute to this will be considered briefly.

Increase of Pulmonary Pressure. Von Euler and Liljestrand (1946) pointed out that hypoxia causes an increase in the pulmonary arterial pressure in animals, and Motley et al. (1947) showed this to be true in man also. There has since been wide acceptance of this phenomenon, which may give rise to misleading results on cardiac catheterization in patients who are hypoxic by reason of sedation or of high altitude. Rotta et al. (1956) studied the effects of altitude on the pulmonary arterial pressure in healthy persons by means of cardiac catheterization. In seven controls at sea-level, the mean pulmonary arterial pressure was $12 \mathrm{~mm} . \mathrm{Hg}$ and the arterial oxygen saturation 98 per cent; in six healthy men normally resident at sea-level but having lived one year at $13,900 \mathrm{ft}$., the figures were 
$18 \mathrm{~mm}$. and 84 per cent, and in seven others native to this altitude, $24 \mathrm{~mm}$. and 80 per cent; and finally, in two men with chronic mountain sickness, the figures were $35 \mathrm{~mm}$. and 71 per cent respectively. These workers did not find the cardiac output was raised at rest, in contrast with the findings in previous studies; and, paradoxically, breathing 35 per cent oxygen did not lower the pulmonary arterial pressure or the pulmonary vascular resistance. The mechanism by which hypoxia produces pulmonary hypertension is by no means clear and will not be discussed here, but it appears to be of importance in the genesis of the raised pulmonary arterial pressure in chronic mountain sickness, cor pulmonale, and in some cases of congenital and acquired heart disease.

Polycythomia (Hurtado, 1932) with its accompanying increase in blood viscosity (Cournand, 1950) also adds to the burden on the heart at high altitude. The frequent finding of right ventricular hypertrophy at necropsy among mountain dwellers (Rotta, 1955) is evidence of increased load on the right side of the heart. Brisket disease, which derives its name from the fact that the brisket, being a dependent part, fills with œdema fluid in heart failure, is a form of cor pulmonale in cattle living at altitudes of over $8000 \mathrm{ft}$. (Pierson and Jensen, 1956): it is apparently the veterinary parallel to chronic mountain sickness. The disease is reversible when the animal is brought to lower altitudes. In guinea-pigs, exposure to the conditions of a low-pressure chamber leads to right ventricular hypertrophy (Valdivia, 1957).

In man decompression chambers have been employed for a number of years to study the effects of low pressure and hypoxia on the circulation. Hurtado et al. (1934) found respiratory difficulty, capillary dilatation in skin and mucosa, tachycardia, and arterial anoxæmia in three subjects placed in a decompression chamber at a pressure equivalent to an altitude of $16,000 \mathrm{ft}$. Guinea-pigs treated similarly showed striking capillary dilatation in the lungs with alveolar distension. Houston (1946) performed daily physiological studies on four men in a decompression chamber over a period of one month towards the end of which a simulated altitude of $29,000 \mathrm{ft}$, was reached without oxygen and $50,000 \mathrm{ft}$. with its aid. Cardiographic studies performed during this time revealed a progressive lowering of the $\mathrm{T}$ wave with increasing altitude up to $16,000 \mathrm{ft}$., but reversal of this trend at higher levels-findings similar to those seen in some cases in this study. No mention was made of axis deviation.

Exertion. Houston (1947) emphasized the enforced inactivity of his subjects in the restricted confines of the decompression chamber, conditions very different from those of climbing with considerable loads in the mountains. Hürliman and Wiggers (1953) thought it was the increase in cardiac output rather than the rise in pulmonary vascular resistance that led to the rise of pulmonary arterial pressure in the hypoxic state. The pumping of large quantities of blood over a long period of time might reasonably be expected to lead to hypertrophy of a ventricle that is unaccustomed to deal with this load, particularly if the resistance of the pulmonary vasculature is increased. Earlier investigators of the effect of exercise on the pulmonary arterial pressure found that it fell (Riley et al., 1948) or did not rise appreciably until the flow exceeded three times the resting value (Cournand, 1950). Later workers however found a slight rise of pulmonary arterial pressure with only moderate increases of cardiac output in normal subjects (Donald et al., 1955).

Physical effort has been said of itself to produce some measure of right axis shift in the electrocardiogram (Reindell, 1938; Beckner and Winsor, 1954), which other authors (Chailley-Bert and Plas, 1956) found to be reversed immediately after the cessation of effort. Peñaloza and Ecchevaría (1957) described some rightward shift of the QRS axis in subjects who had lived at 14,000 ft. for a year; and Peñaloza et al. (1958) noted cardiographic changes that they ascribed to variations in cardiac position and probable overloading of the right ventricle in subjects who were taken by car to $14,000 \mathrm{ft}$. The QRS shift was not of the same order as that recorded here, but again the factor of effort was absent. It seems, therefore, that physical exertion, through its effect in increasing the cardiac output, contributed to the greater degree of right axis shift that we observed compared with the degree found in subjects exposed to the effects of altitude alone.

$T$ Wave Changes in Left Chest Leads. The T wave changes over the left ventricle may have a different explanation, the most likely one being ischæmia of the left ventricular muscle at $19,150 \mathrm{ft}$. It is 
noteworthy that the lowering of the $T$ wave and the diminution in magnitude of the $T$ vector were seen uniformly in the European group but not in the Sherpas. If this change were due to ischæmia it would suggest that the blood supply to the myocardium is better in those who are native to a high altitude, possibly a result of the collateral-stimulating effects of chronic hypoxia and of exercise, or perhaps a racial difference. In Subject 1 (European), where the $\mathrm{T}$ wave change in V4 was greatest, there was associated S-T depression (Fig. 9), yet anginal symptoms were conspicuously absent and the subject felt well.

Electrolyte imbalance occurring under such conditions of stress is an alternative or additional explanation of the $\mathrm{T}$ wave changes in leads over both right and left ventricles, and could account for the apparent inconsistencies in the behaviour of the $T$ waves remarked on earlier. Hypoxia and dehydration both cause tissue katabolism and potassium loss; prolonged exertion and emotional strain increase the secretion of the supra-renal hormones (Bayliss, 1955; Pugh, 1959) and thereby, it would seem, promote potassium depletion: finally, the diet of the mountaineer is restricted, though we have not estimated its potassium content, and his intake of fluid is curtailed by the scarcity of water. These several factors are likely to influence the $T$ waves in the cardiogram, but we are in no position to speak with any authority about them and their elucidation must await further study.

There is a further possibility. The negative $\mathrm{T}$ in $\mathrm{V} 4$ appears to lie in an area of $\mathrm{T}$ positivity, and so fulfils the criterion for isolated T wave negativity described by Grant (1956) in healthy people. Whether or not the forceful impinging of the over-active heart against the chest wall over a period of days at high altitude could lead to such an aberration of ventricular repolarization we do not know, and Grant (1960) says he has never been able to produce this isolated negativity with exercise.

Much remains to be learned about the cardiovascular response to high altitude. The events recorded here represent only one aspect of the picture, and other phenomena that await explanation have been observed in the mountains. Hunt (1953) described periodic breathing of intensity sufficient to interfere with rest during the time of acclimatization. The members of this expedition experienced similar discomfort, accompanied during the hyperpnœic phase by a short but unpleasant sensation of suffocation: this was relieved by sitting up. Houston (1959) saw clinical and radiological evidence of pulmonary odema in a previously healthy young man exposed to high altitude, cold, and prolonged exertion; and there have been occasional unexpected deaths among climbers at heights near $20,000 \mathrm{ft}$. which, from the descriptions given, convey the picture of fatal pulmonary œdema. The response of the human body to life at high altitude is a complicated one, and we have been able to present only a part, and perhaps only a small part, of the whole story.

\section{SUMmARY}

The electrocardiograms of twelve mountaineers were recorded at different altitudes up to 19,150 feet. Right axis deviation and $\mathrm{T}$ wave inversion in the right præcordial leads were found in both European and Sherpa climbers, and S-T segment and T wave changes in the left præcordial leads in members of the European group. The significance of these changes is discussed.

We are grateful to Dr. William Evans for his encouragement and assistance in planning this investigation and in interpreting the results, and to Professor K. W. Donald for help with the text.

The work was made possible by generous grants from the Medical Research Council and the Newcastle Regional Hospital Board. The electrocardiograph was given by the Cambridge Instrument Company, to whom we are also indebted for part of the cost of the colour reproductions. The map of the route is published by the courtesy of the Royal Geographical Society and Fig. 2 and 7 with the permission of E. A. Wrangham, Esq.

\section{REFERENCES}

Ashman, R. (1946). Arch. Inst. Cardiol. Mex., 16, 139.

Bayliss, R. I. S. (1955). Brit. med. J., 1, 495.

Beckner, G. L., and Winsor, T. (1954). Circulation, 9, 835. Chailley-Bert, P., and Plas, F. (1956). Médecine Éducation Physique, et Sport, No. 111. Socéité Médicale Française
d'Éducation Physique et de Sport.

Cournand, A. (1950). Circulation, 2, 641.

Donald, K. W., Bishop, J. M., Cumming, G., and Wade, O. L. (1955). Clin. Sci., $14,37$. 
von Euler, U. S., and Liljestrand, G. (1946). Acta physiol. Scand., 12, 301.

Grant, R. P. (1956). Clinical Electrocardiography. McGraw-Hill. (1960). Personal communication.

Houston, C. S. (1946). U.S. Nav. M. Bull., 46, 1783.

(1959). Personal communication.

and Riley, R. L. (1947). Amer. J. Physiol, 149, 565.

Hunt, Sir J. (1953). The Ascent of Everest. Hodder and Stoughton, London.

Hürlimann, A., and Wiggers, C. J. (1953). Circulation Res., 1, 230.

Hurtado, A. (1932). Amer. J. Physiol., 100, 487.

— Kaltreider, N., and McCann, W. S. (1934). Amer. J. Physiol., 109, 626.

Jones, J. H. E. (1960). Alphine Journal, 65, 1.

Lepeschkin, E. (1951). Modern Electrocardiography. Williams and Wilkins Co.

Motley, H. L., Cournand, A., Werkö, L., Himmelstein, A., and Dresdale, D. (1947). Amer. J. Physiol., $150,315$.

Peñaloza, D. (1958). School of Aviation Medicine, U.S. Air Force, Randolph base, Texas. Report of August 1958. — and Echevarría, M. (1957). Amer. Heart. J, 54, 811. Marticorena, E., and Gamboa, R. (1958). Amer. Heart J., 56, 493.

Pierson, R. E., and Jensen, R. (1956). Diseases of Cattle, p. 717. American Veterinary Publications, Inc.

Pugh, L. G. C. E. (1959). Brit. med. J., 1, 342.

Reindell, H. (1938). Dtsch. Arch. klin. Med., 181, 485.

Riley, R. L., Himmelstein, A., Motley, H. L., Weiner, H. M., and Cournand, A. (1948). Amer. J. Physiol., $152,372$.

Rotta, A. (1955). Rev. peru. Cardiol., 4, 71.

Canépa, A., Hurtado, A., Velasquez, T., and Chávez, R. (1956). J. appl. Physiol., 9, 328.

Valdivia, E. (1957). Circulation Res., 5, 612. 